IZA DP No. 1060

Complex Production Processes and Wage Inequality

Tuomas Pekkarinen

March 2004 


\title{
Complex Production Processes and Wage Inequality
}

\author{
Tuomas Pekkarinen \\ Nuffield College, Oxford \\ and IZA Bonn
}

\section{Discussion Paper No. 1060 \\ March 2004}

\author{
IZA \\ P.O. Box 7240 \\ 53072 Bonn \\ Germany \\ Phone: +49-228-3894-0 \\ Fax: +49-228-3894-180 \\ Email: iza@iza.org
}

\begin{abstract}
Any opinions expressed here are those of the author(s) and not those of the institute. Research disseminated by IZA may include views on policy, but the institute itself takes no institutional policy positions.
\end{abstract}

The Institute for the Study of Labor (IZA) in Bonn is a local and virtual international research center and a place of communication between science, politics and business. IZA is an independent nonprofit company supported by Deutsche Post World Net. The center is associated with the University of Bonn and offers a stimulating research environment through its research networks, research support, and visitors and doctoral programs. IZA engages in (i) original and internationally competitive research in all fields of labor economics, (ii) development of policy concepts, and (iii) dissemination of research results and concepts to the interested public.

IZA Discussion Papers often represent preliminary work and are circulated to encourage discussion. Citation of such a paper should account for its provisional character. A revised version may be available on the IZA website (www.iza.org) or directly from the author. 


\section{ABSTRACT \\ Complex Production Processes and Wage Inequality*}

This paper studies how changes in the complexity of the firms' production technologies affect wage differences between and within tasks. In a production process where tasks are complementary, the employer may have an incentive to pay higher wages when using more complex technologies because the output of such processes is more effort-sensitive. We use linked employer-employee data from the Finnish metal industry. These data provide quantified information on the complexity of the tasks of individual workers. The average complexity of the tasks in the firm is used as a proxy for the complexity of the production process. We estimate the effect of the complexity of the production process on hourly wages at different levels of complexity of the worker's own tasks and at different parts of the conditional wage distribution within tasks. We find that the complexity of the firm's production process increases wages in all the tasks but that there are no significant differences in this effect across tasks. Finally, the effect of the complexity of the production process tends to be stronger at the high end of the conditional wage distribution within tasks.

JEL Classification: J31, O33

Keywords: technological complexity, wage inequality

Tuomas Pekkarinen

Nuffield College

New Road

Oxford, OX1 1NF

United Kingdom

Tel.: +44 1865278662

Email: tuomas.pekkarinen@nuffield.oxford.ac.uk

\footnotetext{
* I would like to thank David Autor, Alberto Dalmazzo, Karolina Ekholm, Andrea Ichino, Markus Jāntti, Francis Kramarz, and Frank Vella for helpful comments. All the remaining mistakes are mine. I am grateful to the Academy of Finland and the Yrjo Jahnsson Foundation for financial support and to the Confederation of Finnish Industry and Employers (Teollisuus ja tyōnantajat) for the permission to use the data. The data are archived at the Labour Institute for Economic Research, Helsinki, and permissions to use the data are controlled by the Confederation of Finnish Industry and Employers. The programs used to generate the results can be obtained from the author.
} 


\section{Introduction}

The increasing wage inequality in the industrialized world has raised a lot interest in recent years. Although patterns vary across countries, one usually finds that wage inequality has increased both between and within different groups of workers and tasks. The consensus view in the literature is that these changes in the wage structure are, at least to some extent, linked to technological changes. ${ }^{1}$

Typically, technological innovations are seen as affecting the wage structure through changes in the task content of jobs. The adoption of information technology, for example, can affect wages in certain jobs by making their task content more complex. But a change in the task content is not the only channel through which the adoption of new technologies can affect wages. More complex production processes often imply organizational changes that make certain jobs in the process more crucial, even if their task content does not change. Thus, the fact that the production process where the worker is involved in has become more complex may also have an effect on the wages in jobs where task content is left unaltered.

In this paper, we study how individual hourly wages are affected by changes in the complexity of one's co-workers' tasks, holding the complexity of the individual's own tasks constant. The idea is that the average complexity of one's co-workers' tasks acts as a proxy for the overall complexity of the production process in the firm. Our aim is to examine how changes in the complexity of the production process affect the wage inequality both between and within tasks. First, we study whether the complexity of the production process has any effect on wages and whether this effect varies between tasks of different complexity. Second, we examine the variation of this effect along the conditional wage distribution within tasks.

We have access to a unique data-set that provides information on the complexity of the tasks of each individual worker. In the Finnish metal industry, the evaluation of the complexity of the tasks involved in each job is a crucial part of the wage determination process. According to this evaluation a job-specific minimum wage is attached to each job in this industry. We have data on the whole metal industry population during 1996-2000 where these minimum wages are observed along with final wages earned by each worker.

Theoretically, differences in the degree of complexity of the production processes can cause wage differentials when tasks are complementary in the production process. This means that higher effort in one task increases the marginal productivity of effort in the rest of the tasks as well. ${ }^{2}$ A famous example of a production process with these characteristics is the O-ring production function by Kremer (1993). In Kremer and Maskin (1996), this production function is extended to allow for differential effort-sensitivity of tasks. Dalmazzo (2002) has augmented these kinds of production functions with an efficiency wage mechanism, making the effort exerted by the workers an increasing function of the wage.

The argument is that the combination of complementarity and efficiency wages creates a situation where the employers who switch to a more complex production process have an incentive to pay higher wages to their workers. This happens because a failure in any of the tasks will jeopardize the effort by the more complex production line. Furthermore, the incentive to pay higher wages will be stronger, the more effort-sensitive the output is. Hence, if tasks differ in the effort-sensitivity of output, the increasing complexity of the production process will increase wage differentials between tasks.

\footnotetext{
${ }^{1}$ On evidence regarding the recent trends and their interpretation, see Acemoglu (2002) as well as Katz and Autor (2001). Eriksson and Jäntti (1997) and Uusitalo (2002) provide evidence on Finland.

${ }^{2}$ Complementary production processes have been studied in a general context by Milgrom and Roberts (1990).
} 
It is a well known fact that inter-firm wage differentials are related to observable differences in the production technologies. This result has been reported in the studies such as Dunne, Foster, Haltiwanger, and Troske (2000), Doms, Dunne, and Troske (1997), as well as Dalmazzo and Scaramozzino (2000) that use firm-level data to study the relationship between wages and production technology. On the individual level, several papers have looked at how explicit changes in the task content affect wages. A very influential study by Krueger (1993) uses micro-data to study the effect of computer use on wage structure and finds that these kind of changes in tasks tend to increase wages. However, according to more recent results by DiNardo and Pischke (1997) as well as Entorf, Gollac, and Kramarz (1999), this effect is probably due to unobserved individual heterogeneity.

What is common to the empirical studies mentioned above is that they are unable to separate the effect of the change in the complexity of the production process on wages from the changes in the task content in the worker's own job. In this paper, our aim is to separate these two effects on wages and study how the direct effect of the complexity of the production process varies within and between tasks. ${ }^{3}$

The results presented here are related to a recent branch of literature that studies the effects of technological changes on the organization of the firm. Autor, Levy, and Murnane (2003) point out that the recent technological innovations have not only substituted for certain routine tasks but also complemented non-routine tasks performed by workers. Hence, technological changes have an impact on the whole production process and may change the role of certain tasks in it. For instance, Bresnahan, Brynjolfson, and Hitt (2002) find that the adoption of information technology is complementary to workplace reorganization and introduction of new products. Finally, Bartel, Ichniowksi, and Shaw (2000) conduct plant visits in the US medical, valves, and steel industries to obtain information about technological and organizational changes. Their findings confirm the indirect evidence of previous studies. All these results imply that technological innovations may affect the role of different tasks in the organization of the firm without directly affecting their task content.

The structure of this paper is as follows. In the following section, we will borrow from Kremer and Maskin (1996), Dalmazzo (2002), and Dalmazzo and Scaramozzino (2000) and present a version of the O-ring production function that exhibits differential sensitivity to worker's effort and discuss the implications of the efficiency wages in this context. In the third section, the data are presented. Particular emphasis will be put on the explanation of the variables of interest. We explain what is meant with an occupationrelated wage in this industry and why we believe that this is a valid measure of the complexity of the tasks the worker is performing and how it can be used to construct a measure of the complexity of the firm's production process. In the fourth section, we present the results from regressions of wages on the complexity of the production process. We focus first on the effect of the complexity of the production process in different tasks and then at different parts of the conditional wage distribution within tasks. The fifth section concludes.

\section{Theoretical background}

In a complementary production technology the efforts of workers in different tasks are dependent on each other. Outstanding performance in one of the tasks raises the value of successful performance in rest of the tasks as well. Conversely, mistakes in any of the

\footnotetext{
${ }^{3}$ Pekkarinen (2002) is a study that uses an earlier and smaller sample from the same data that are used here to study the effect of the complexity of the production process on wages. However, the variation of this effect between and within tasks is not explored.
} 
tasks can significantly reduce the value of the final product even though the rest of the tasks were completed successfully.

A famous example of a production function with these characteristics is the O-ring production function by Kremer (1993). The O-ring production function represents a particular kind of complementarity where production consists of a number of tasks all of which have to be completed for the final product to have full value. If a mistake occurs in any of the tasks, the value of the final product is reduced to zero. Kremer and Maskin (1996) have extended this production function to a case where tasks are differentially sensitive to worker's effort. Dalmazzo (2002) has studied the implications for wage differentials in a case where the probability of successful completion of the task is an increasing function of the wage paid.

\subsection{Workers}

Consider workers who are heterogeneous in ability. We follow here Dalmazzo (2002) and assume that the probability that worker $i$ completes his or her tasks successfully, $q_{i}$, depends on the wage paid to the worker, $w_{i}$, and his or her ability, $\alpha_{i}: q_{i}=q\left(w_{i}, \alpha_{i}\right)$ such that $\frac{\partial q}{\partial w}>0, \frac{\partial^{2} q}{\partial w^{2}}<0, \frac{\partial q}{\partial \alpha}>0$ and $\frac{\partial^{2} q}{\partial w \partial \alpha}>0$. The effect of wage on the probability of success can be justified with familiar efficiency wage arguments. Furthermore, assume that workers face no labour-leisure choice and supply labour inelastically.

\subsection{Firms}

In line with the discussion above, consider a production process of firm $j$ that consists of $n_{j}$ tasks out of which $l_{j}$ are "easy" and $n_{j}-l_{j}$ are "hard". A hard task is more sensitive to worker's effort. That is, for a given level of effort, the probability of successful completion of the task is higher in the easy task.

In order to keep the notation as simple as possible, we assume that for a given level of effort the probability of success in the easy task is equal to $q\left(w_{i}, \alpha_{i}\right)$ and $q\left(w_{i}, \alpha_{i}\right)^{z}$ in the hard task, where $z>1$. The technologies chosen by firms differ in the degree of complexity. ${ }^{4}$ Interpret the complexity as the number of difficult tasks involved in the production.

Suppose that the technologies of all the firms are such that tasks are complementary. As a particular example consider the case of O-ring production function with easy and hard tasks. In this case

$$
y_{j}=n_{j} B q\left(w_{i}, \alpha_{i}\right)^{l_{j}}\left[q\left(w_{i}, \alpha_{i}\right)\right]^{z\left(n_{j}-l_{j}\right)}
$$

where $y_{j}$ is the output by firm $j$ and $B$ is the output per task if all the tasks are completed successfully.

When there are both heterogeneous workers and heterogeneous tasks the employer faces an assignment problem. In order to illustrate, suppose that there is a firm with only one easy and one hard task and the employer has to decide to which task assign his or her two employees who have abilities $\alpha_{H}$ and $\alpha_{L}$ such that $\alpha_{H}>\alpha_{L}$. One can easily see that the employer will assign the worker of type $\alpha_{H}$ to the hard task and the worker of type $\alpha_{L}$ to the easy task because $q\left(\alpha_{L}\right)\left[q\left(\alpha_{H}\right)\right]^{z}>q\left(\alpha_{H}\right)\left[q\left(\alpha_{L}\right)\right]^{z}$. Sattinger (1979) has analyzed the general case with a continuous ability distribution. It can be shown that as long as $\frac{\partial^{2} q}{\partial w \partial \alpha}>0$, more able workers will be assigned to tasks that are more sensitive to effort.

\footnotetext{
${ }^{4}$ We assume this variation in production technologies to be exogenous.
} 
The firm's problem is to set wages such that each worker in each task exerts the optimal amount of effort:

$$
\max _{\left\{w_{L}, w_{H}\right\}} n_{j} B q\left(w_{L}\right)^{l_{j}}\left[q\left(w_{H}\right)\right]^{z\left(n_{j}-l_{j}\right)}-w_{L} l_{j}-w_{H}\left(n_{j}-l_{j}\right)
$$

Which yields the first-order conditions:

$$
\begin{gathered}
\frac{\partial \pi}{\partial w_{L}}=y_{j} \frac{\partial q}{\partial w_{L}}-q\left(w_{L}\right)=0 \\
\frac{\partial \pi}{\partial w_{H}}=z y_{j} \frac{\partial q}{\partial w_{H}}-q\left(w_{H}\right)=0
\end{gathered}
$$

Thus, (3) and (4) together imply that $\frac{q^{\prime}\left(w_{L}\right)}{q\left(w_{L}\right)}=z \frac{q^{\prime}\left(w_{H}\right)}{q\left(w_{H}\right)}$ from which it follows that $w_{H} \geq w_{L}$. In other words, workers performing more sensitive tasks will be paid higher wages. It is also straightforward to show that $\frac{\partial w_{i}}{\partial\left(n_{j}-l_{j}\right)}>0$ for all $i$, if $\frac{\partial y}{\partial n_{j}}>0$, which is true in a free-entry equilibrium. That is, identical workers in identical tasks will earn different wages if the firms they are employed in have adopted production processes of different complexity. Furthermore, under plausible assumptions about the shape of $q\left(w_{i}\right)$ it holds that $\frac{\partial w_{H}}{\partial\left(n_{j}-l_{j}\right)}>\frac{\partial w_{L}}{\partial\left(n_{j}-l_{j}\right)}>0 .{ }^{5}$ The wages of workers in more effort-sensitive tasks will be increased more than the wages of workers in less sensitive tasks.

A combination of a technology where tasks are complementary and an efficiency wage mechanism can thus give rise to two kind of wage differentials. First, identical workers doing identical jobs earn different wages if they are employed in firms that use different production technologies. Second, the wage differences caused by differences in the complexity of the production processes will be larger within the tasks where output is more sensitive to worker's effort.

\section{The data}

The data that we use in this paper come from the wage records of the Confederation of Finnish Industry and Employers (Teollisuus ja työnantajat). Each year a survey is conducted among the member employers of the confederation and the information is gathered in the wage records. The wage records contain detailed information on the wages and working hours of all the workers who are employed in the firms affiliated with the confederation. In the case of metal industry in Finland, this covers practically all the firms in the industry.

In this paper, we use 1996-2000 data on the whole blue-collar metal industry worker population. After ruling out some workers because of missing or high probability of false information we end up with a panel that has 315935 employee/year observations containing information on 93370 different individual workers. ${ }^{6}$ Workers were distributed in 399 different firms.

The wage records' data on wages and working hours can be considered as exceptionally reliable since the information comes, in principle, directly from the firms'.wage accounts. On the other hand, the information on the individual characteristics is rather scarce. Only gender, age, and seniority can be identified. Perhaps the most disturbing feature of the data is the lack of variables for individual's education. ${ }^{7}$ Table 1 gives descriptive statistics on the whole sample as well as on various sub-samples used in the analysis below.

\footnotetext{
${ }^{5} \mathrm{~A}$ sufficient condition for $\frac{\partial w_{H}}{\partial\left(n_{j}-l_{j}\right)}>\frac{\partial w_{L}}{\partial\left(n_{j}-l_{j}\right)}>0$ to hold is that $\left|\frac{q^{\prime \prime}\left(w_{L}\right)}{q\left(w_{L}\right)}\right|>\left|\frac{q^{\prime \prime}\left(w_{H}\right)}{q\left(w_{H}\right)}\right|$.

${ }^{6}$ Altogether 8178 employee/year observations (2.5\%) were dropped because of potentially false or missing data.

${ }^{7}$ We restrict our analysis on blue-collar workers. It is reasonable to assume that this population is fairly homogeneous with respect to formal education.
} 


\subsection{Wage determination in the Finnish metal industry}

The data on metal industry are particularly useful for the analysis of the issues discussed in the previous section. The reason for this is the peculiar wage determination mechanism in the Finnish metal industry. The employers and the trade union have established a procedure that provides information on the complexity of each job and productivity of each worker in this industry.

In the Finnish metal industry the general guidelines of the wage determination are set in the national level collective agreement that is negotiated between the central employer organization and the trade union. According to the collective agreement, wages should be determined by the complexity of the job, individual performance of the worker given the requirements of the job, and by various individual and firm-specific arrangements. The same rules should be applied in all the firms.

The complexity of the job specifies a job-specific minimum wage for each worker. This minimum level is called the occupation-related wage. Worker's individual performance affects the wage outcome through a personal bonus of 2 to $17 \%$ on top of the occupationrelated wage. The determination of the final wage outcome takes place at the firm level. An individual .firm has considerable scope to choose its wage levels as long as it stays above the minimum levels set by the collective agreement.

\subsection{Occupation-related wages}

In this paper, we use occupation-related wages as our complexity measure. Occupationrelated wages are determined in the following way. The first stage of the wage determination is the evaluation of the jobs in the industry. This is carried out by a group of experts who should consider various aspects of the jobs and assign them points according to their complexity. The complexity level is based on three criteria: 1) how long does it take to learn the tasks involved with the job, 2) what is the degree of responsibility involved with the job, and 3) what are the working conditions. The outcome of the evaluation should be independent of the characteristics of the workers and does not therefore change when the individual on the job changes.

Based on the evaluation of jobs an occupation-related wage is determined for each job in the collective agreement. The more demanding the job, that is the more complexity points it gets, the higher is the corresponding occupation-related wage. This is the feature of the data that we use in the analysis. Basically there should be a one-to-one mapping from the occupation-related wages to the complexity points.

The fact that we measure the complexity of worker's tasks in the wage space creates several problems that have to be addressed. First of all, it is crucial for our analysis that the scale with which the complexity is measured does not change in time. However, the examination of the yearly distributions of the occupation-related wages revealed that occupation-related wages were increased almost every year by a general growth factor. It is clear that these increases are not related to changes in tasks.

We transformed the data by grouping the workers according to their occupationrelated wages in yearly cross-sections and analyzing the distributions of year-to-year changes of occupation-related wages in each group. This revealed that for most of the workers within the group the changes in occupation-related wages were identical. Hence, we interpreted the group mode of this change as the change in the occupation-related wage that was not related to changes in the tasks. The occupation-related wages were then corrected by subtracting the within group mode-change from the corresponding occupation-related wages. Since, these wage changes were naturally also present in the final wages, the same stationarization was done for the final wages as well.

Another potential problem with the use of occupation-related wages as a complexity 


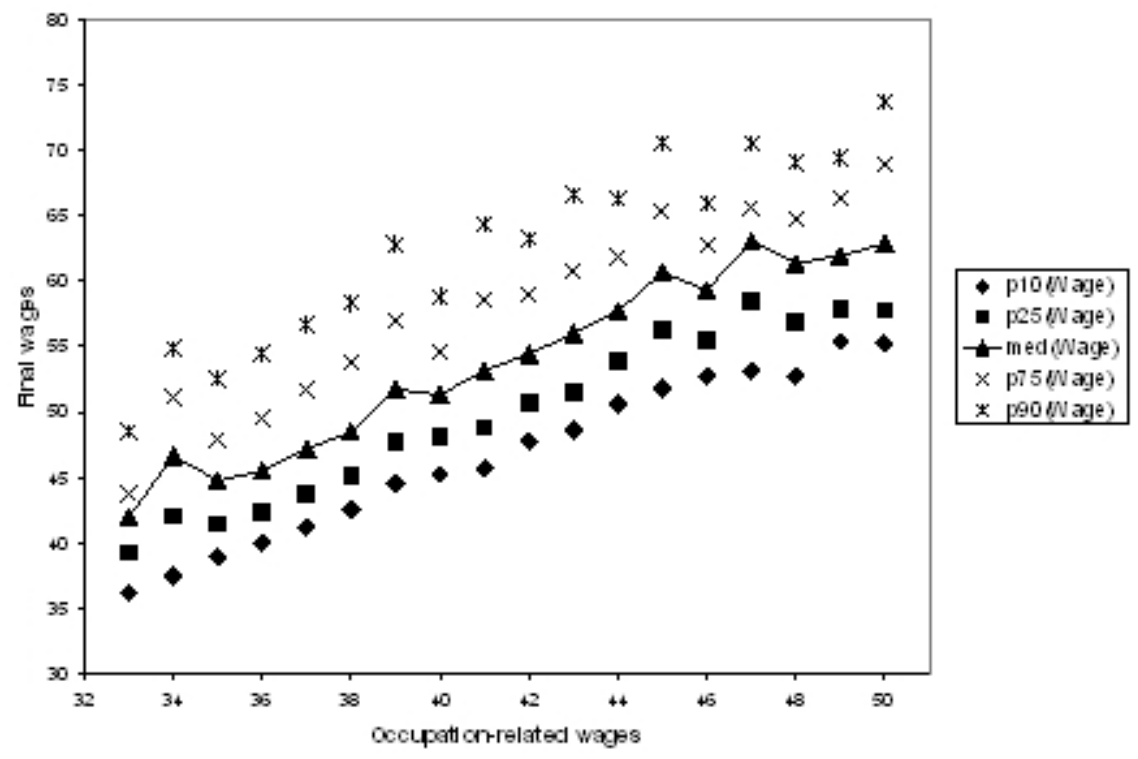

Figure 1: Distribution of wages as a function of the complexity of the worker's own tasks.

measure is the possibility that the occupation-related wages are set by just splitting the final wages into non-overlapping intervals. If this was true, the occupation-related wages would not reflect the complexity of the tasks, since simple wage increases would appear to change the tasks of the worker.

In figure 1, we explore the relationship between the final wages and the occupationrelated wages using the cross-sectional data from 1996. Figures for the rest of the years were virtually identical. The figure plots complexity groups and their wage distributions expressed by within-group median as well as 10th, 25th, 75 th, and 90th percentiles. The complexity groups were formed by aggregating the occupation-related wages into integers. There is considerable overlapping in the upper percentiles of the wage distributions which seems to indicate that occupation-related wages are not determined by final wages.

To further assure that this is not the case, one can look at the relationship between the movement of workers across different levels of occupation-related wages and the changes in final wages. In tables $2 \mathrm{a}$ and $2 \mathrm{~b}$, we look at workers who move upwards the complexity axis. We call these workers "promotees". Table 2 a reports the positions of these workers in the within-firm wage distribution of the group they parted from. Similarly, table $2 \mathrm{~b}$ reports their position in the within-firm wage distribution of the arrival group. Groups were constructed in the same way as in figure 1.

If occupation-related wages were simply determined by .final wages, we should expect to see most of the movement taking place from the top of the wage distribution of the departure group to the bottom of the wage distribution of the arrival group. This is clearly not the case here. In fact, table 2 a reveals that most of the movement of promotees takes place from lower deciles of the departure group. Moreover, these workers also seem to spread more or less evenly across the deciles of the wage distribution of the arrival group, as can be seen from table $2 \mathrm{~b}$. It seems that occupation-related wages are not determined by final wages.

Finally, if the average occupation-related wage really measures the complexity of the 
firm's production process, it seems reasonable that one should not observe substantial changes within firms during such a short period that we are studying. This seems to be the case here. Year-to-year variation in the firm-level means of occupation-related wages was small and, especially among larger firms, concentrated around zero.

We interpret the evidence reported above as justifying the use of occupation-related wages as a measure of the complexity of the tasks in the job. Thus, for each individual the occupation-related wage measures the complexity of the tasks he or she is performing and the average occupation-related wages of his or her coworkers measures the complexity of the production process in the firm.

\subsection{Complexity and wage inequality trends in the Finnish metal industry}

We are unable to explore whether there was any overall trend in the complexity of the tasks in this industry during 1990's. This is because the scale with which we measure the complexity is bounded from above and constant over time. However, we can say something about the overall trend in wage inequality and the segregation of tasks of different complexity across firms.

Standard measures of wage inequality, such as standard deviation of wages and the ratio of the 10th and 90th percentiles of wages, remained almost constant during the whole decade. There is no indication whatsoever, that wage inequality would have increased in the Finnish metal industry during these years. However, there are some signs of increasing segregation of both tasks and wages across firms. The index of segregation, suggested by Kremer and Maskin (1996), that measures the extent of within-firm correlation of the complexity of the tasks, increased from 0.31 in 1990 to 0.42 in 2000. Similarly, the segregation of wages increased from 0.31 in 1990 to 0.45 in 2000 . There are signs that firms were becoming increasingly different with respect to each other in terms of both technology and wages.

\section{The results}

The theoretical background discussed in the second section suggested that wages should increase with the degree of complexity of the firm's production process in all the tasks. Furthermore, this effect should be more pronounced in the tasks where output is more sensitive to worker's effort. Increasing variation in the complexity of the production technology across firms should thus lead to increasing wage differentials both within and between tasks. In this section, we examine these implications using the occupation-related wages as a measure of the complexity of the worker's tasks.

\subsection{Estimating the effect of the complexity of the production process on wages}

The wage equation we are estimating is very similar to the one studied by Abowd, Kramarz, and Margolis (1999):

$$
w_{i, t}=\beta \bar{n}_{J(i, t), t}+\eta n_{i, t}+\gamma X_{i, t}+\alpha_{i}+\delta_{J(i, t)}+\epsilon_{i, t}
$$

where $w_{i, t}$ is the log of real hourly wage of an individual $i$ at time $t, \bar{n}_{J(i, t), t}$ is our measure of the complexity of the production process of the firm $J(i, t)$, where $i$ is employed at $t, n_{i, t}$ measures the complexity of $i$ 's own tasks at $t, X_{i, t}$ is a set of observable individual and firm characteristics, and $\epsilon_{i, t}$ is the residual. The individual and firm specific fixed effects are denoted by $\alpha_{i}$ and $\delta_{J(i, t)}$ respectively and are assumed to be fixed in time.

As was explained in the third section, we measure the complexity of the worker $i$ 's task with the log of his or her occupation-related wage and the complexity of the production 
process with the average of $i$ 's co-workers' occupation-related wages in the firm $\delta_{J(i, t)}$. In $X_{i, t}$ we include quadratic terms of the age and seniority of the worker, a dummy for female worker and newcomer in the industry, and the number of employees in the firm. In addition to these variables $X_{i, t}$ also contains the average personal bonuses of $i$ 's co-workers. This variable is introduced to control for the firm's propensity to pay high wages. We want the average bonuses to capture the effect of this propensity and $\beta$ to reflect the pure effect of the average complexity.

The theoretical discussion suggested that the employer will assign the most able persons to more complex tasks. This is why it seems plausible to allow for $E\left[\alpha_{i} n_{i, t}\right] \neq 0$. Similarly, it is likely that unobserved firm effects $\delta_{J(i, t)}$ are correlated with the complexity of the firm's production process. Hence, the estimation of (5) by OLS in levels yields biased estimates.

The typical solution to these endogeneity problems is to estimate (5) by OLS in first differences: ${ }^{8}$

$$
\Delta w_{i, t}=\beta\left(\bar{n}_{J(i, t), t}-\bar{n}_{J(i, t-1), t-1}\right)+\eta \Delta n_{i, t}+\gamma \Delta X_{i, t}+\left(\delta_{J(i, t)}-\delta_{J(i, t-1)}\right)+\Delta \epsilon_{i, t}
$$

where individual fixed effects are wiped away by differencing and firm fixed effects are identified by observations on workers who move from one firm to another. For OLS on this equation to yield unbiased estimators one needs to assume that $\Delta \epsilon_{i, t}$ is not correlated with the first differences of the explanatory variables. This basically implies that the movement of workers between firms is exogenous. Most importantly, we need to assume that $E\left[\epsilon_{i, t-1} \bar{n}_{J(i, t), t}\right]=0$ and $E\left[\epsilon_{i, t-1} \delta_{J(i, t)}\right]=0$. That is, we want to avoid the situation where the workers who move to high complexity or otherwise attractive firms at $t$ are workers with high $\epsilon$ 's at $t-1$.

In this paper, we are interested in the effect of a variable that varies both between and within firms. Thus, one way of avoiding the problem of the endogeneity of moving decisions is to estimate the equation (6) with the observations of workers who stay in the same firm between $t-1$ and $t$. That is, workers for whom $\delta_{J(i, t)}=\delta_{J(i, t-1)}=j$. We have observations on 210206 episodes where the worker remains in the same firm involving 70 907 individuals. In this case the equation (6) takes the following form:

$$
\Delta w_{i, t}=\beta \Delta \bar{n}_{J(i, t), t}+\eta \Delta n_{i, t}+\gamma \Delta X_{i, t}+\Delta \epsilon_{i, t}
$$

The firm fixed effects are now dealt with in the same way as the individual fixed effects. The OLS on this equation yields unbiased estimates if $E\left[\Delta \epsilon_{i, t} \Delta \bar{n}_{J(i, t), t}\right]=0$. While this assumption may seem relatively plausible, the problem with the equation (7) is that the variation in the complexity of the production process within firms, $\Delta \bar{n}_{J(i, t), t}$, is very small. ${ }^{9}$ Hence, it is difficult to identify $\beta$ with only observations on workers who stay within the firms.

When the estimation of $\beta$ relies on the observations on firm-to-firm movers, the plausibility of the assumption concerning the exogeneity of these moving decision depends on the set of workers on which the equation (6) is estimated. Basically, one would like to have a set of workers that is randomly selected to leave the current employer and randomly assigned to a new employer. Clearly, these kind of situations are not available here. Instead, we have decided to choose two sets of workers who change firms in these

\footnotetext{
${ }^{8}$ This strategy is followed for example by Krueger and Summers (1988), Murphy and Topel (1990), Abowd, Kramarz, and Margolis (1999), and Entorf, Gollac, and Kramarz (1999). Gibbons and Katz (1992) as well as Goux and Maurin (1999) also discuss the problems involved with this strategy.

${ }^{9}$ After all, this was a piece of evidence that we used to justify the use of average occupation-related wages as our measure of the complexity of the production process.
} 
data: one where the exogeneity assumptions seems least likely to hold and the one where it seems most plausible.

We call the first group of workers "voluntary movers". These are workers who move from a firm that does not close down (ie it continues to exist in the panel after the worker has left) to a firm that already existed before they arrived. Moreover, these workers are usually solitary movers. That is, they are not involved in situations where, for example, an entire branch of one firm is taken over by another. We think that these workers are as close as one can get to a voluntary moving decisions in these data. There were 2326 moving episodes like this in the data between 219 firms.

The second group, which we call "mergers", are workers who have moved to an already existing firm from a firm that closed down along with the majority of the workers in the old firm. These are situations where more than $50 \%$ of the workforce of a closed firm are absorbed by another firm. We think that these workers are closest that one can get to a group of workers who change firms because of exogenous reasons and who are also assigned to a new firm more or less exogenously in these data. There were 1720 moving episodes like this in the data between 31 firms.

In Table 4, we present results from different specifications of our wage equation. As a benchmark case we present the results from the OLS estimation of (5) in levels in the first column. We then estimate the first differenced equation for the three groups of workers defined above. First, as an approximation of the "lower bound" of the estimate of $\beta$, we present the results from the equation (7) using the data on workers who stay in the same firm between $t$ and $t-1$ in the second column. Second, we report the estimates of the equation (6) for the voluntary movers and mergers in the third and fourth column respectively. One would expect the endogeneity bias to be most severe in the group of voluntary movers, thus yielding an "upper bound" of the estimate of $\beta$, whereas it should be less of a problem in the group of workers involved in mergers.

The OLS estimate of $\beta$ from equation (5) using all the available data is 0.30 and significant. As was to be expected, estimating the wage equation with the sample of workers who stay in the same firm in first differences yields a considerably smaller estimate of $\beta, 0.18$. Furthermore, this effect is only marginally significant. When we use the sample of "voluntary" movers and estimate the wage equation in first differences with a full set of firm dummies, we get almost an implausibly large effect of the complexity of the production process, 0.94 . We interpret that this reflects the endogeneity of the voluntary moving decisions. Finally, using the small merger sample yields a positive effect, 0.31, that is close to the estimate from the stayer sample. This effect is not significant which is not surprising since the firm complexity varies only across 17 firms that close down in the merger sample. In the following, we explore the heterogeneity of the effect of the complexity of the production process.

\subsection{The effect of the complexity of the production process in different tasks}

The theory discussed in the second section implied that the effect of the complexity of the production process should be stronger in the tasks that are more effort-sensitive. There is no direct measure of the effort-sensitivity of tasks in these data. Indeed, the only dimension in which tasks differ is the degree of complexity. However, based on the description the data, it seems natural to assume that output is more sensitive to worker's effort in more complex tasks. Therefore, we will explore the variation of the effect of the complexity of the production process across tasks of different complexity.

We decided to split the workers into five complexity quantiles according to the tasks that they perform. In figures 2 and 3, we have plotted the relationship between the average wages of workers in two of these groups and the average complexity of the all the 


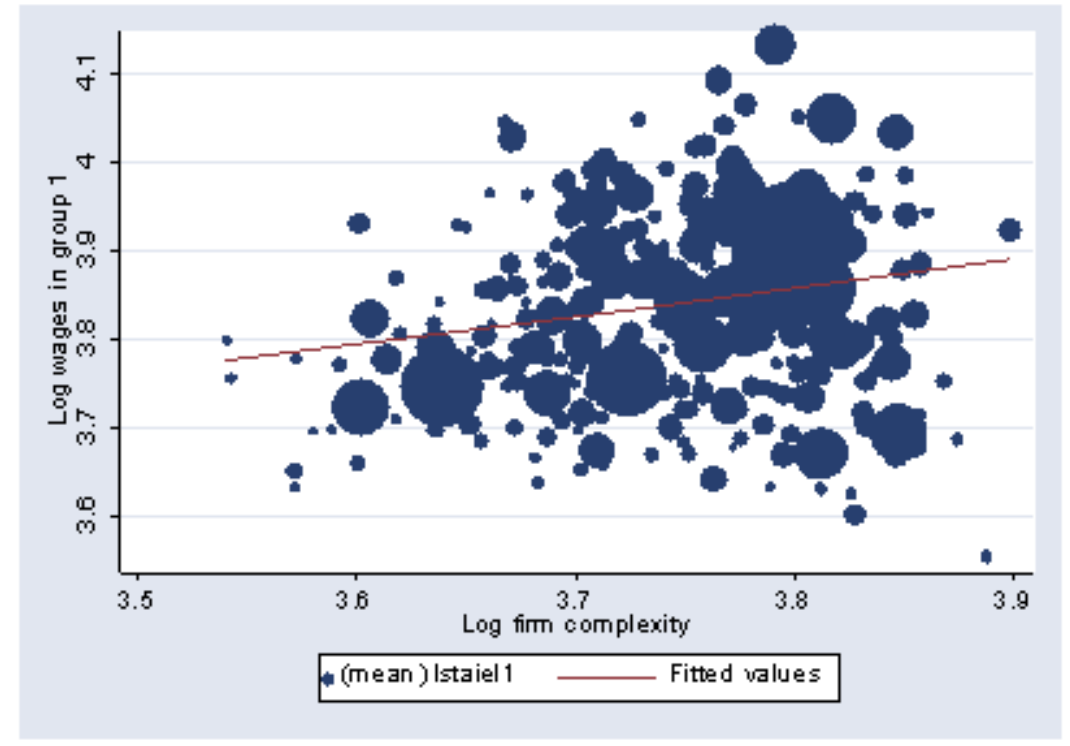

Figure 2: The relationship between average wages of workers in the lowest complexity group and average complexity of all the tasks in the firm. 1996 cross-section.

tasks in the firm. Thus, the figures illustrate the relationship of wages and the complexity of the production process for groups of workers that perform tasks of more or less similar complexity. In figure 2, we have chosen the workers in the lowest of these five complexity quantiles, ie the workers who perform the least complex tasks in this industry. The workers whose wages are plotted against the complexity of the firm in figure 3 , on the other hand, come from the highest complexity quantile. The sizes of circular shapes in the figures reflect the total number employees in the firm.

In line with the results above, both figures show that the average wages are increasing in the average complexity of the tasks in the firm. Regardless of the tasks that they are performing, the workers earn higher wages in firms that have more complex production processes. However, the relationship also seems to be somewhat steeper in figure 3 than in figure 2, suggesting that the wages of workers in more complex tasks increase more with the average complexity of the firm's tasks.

To further explore the variation of the effect of the complexity of the production process between tasks, we interacted the effect of the complexity of the production process with dummies for our five complexity groups. That is, we ran the following version of the wage equation (5):

$$
w_{i, t}=\sum_{k=1}^{5} N_{k} \beta \bar{n}_{J(i, t), t}+\eta n_{i, t}+\gamma X_{i, t}+\alpha_{i}+\delta_{J(i, t)}+\epsilon_{i, t}
$$

where $N_{k}(k=1, \ldots, 5)$ are a set of dummy variables that take value one if the individual is performing tasks that belong to group $k$. If the estimation yields very different estimates of $\beta$ 's across groups, the pattern observed in figures 2 and 3 is confirmed.

Table 4 reports the $\beta$ coefficients for the five complexity groups and the main effect of the individual complexity from the OLS estimation of (8) in levels with all the available data and in first differences with the stayer sample. The coefficients reported in table 4 are very similar across groups. There does not appear to be large differences in the effect 


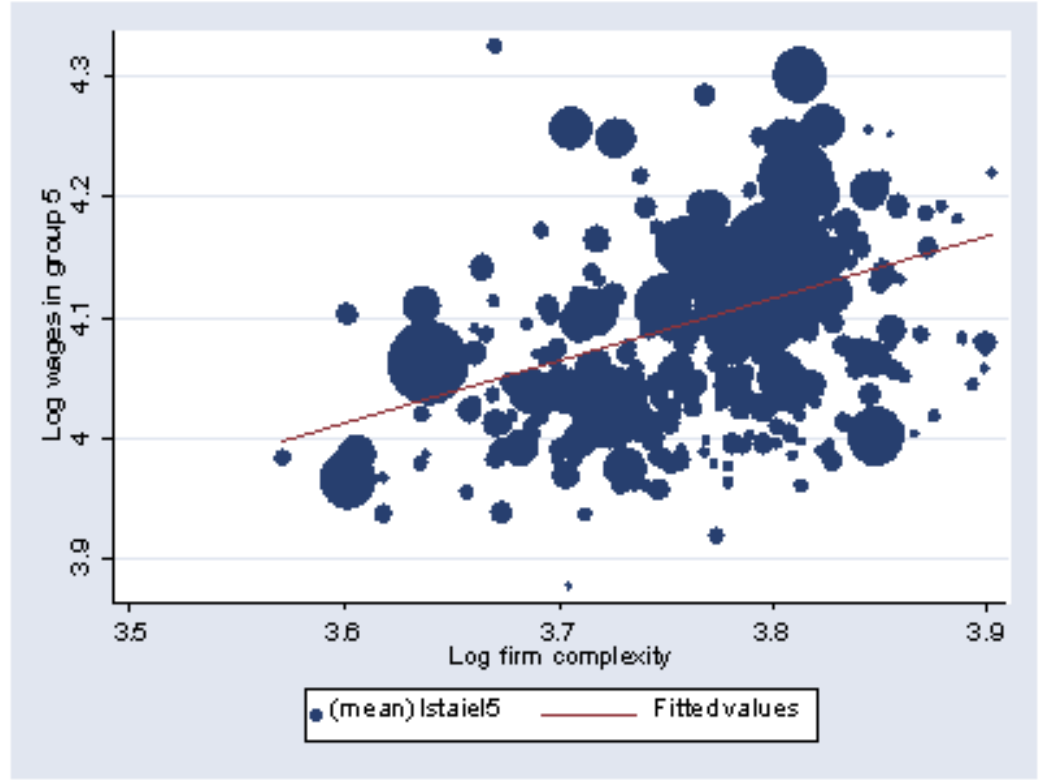

Figure 3: The relationship between the average wages of workers in the highest comlexity group and the average complexity of all the tasks in the firm, 1996 cross-section.

of the complexity of production process across tasks. Accounting for individual and firm fixed effects in the second column does not change this pattern of results. Hence, the differences in the complexity of the production process do not seem to contribute to the wage differentials between the tasks. As the firms switch to more complex production processes, the wages are increased in all the tasks so that the differentials between the tasks are left almost unaltered.

\subsection{The effect of the complexity of the production process within tasks}

But the effect of the complexity of the production process on wages can vary across other attributes of tasks than simply complexity. After all, complexity might not be capturing all the characteristics of the tasks that make the output in the task more effort sensitive. Although the complexity of the tasks is the only task characteristic that we observe in our data, we can still explore the heterogeneity of the effect of the complexity of the production process on wages by studying how it varies along the conditional wage distribution within tasks.

In figure 4 , we have taken the workers in the group 3 of our five complexity groups - that is, the workers with tasks of medium complexity - and plotted the distribution of wages in this group at various values of the complexity of the production process in 1996. The idea is to roughly control for the complexity of the individual's own tasks by taking only a group of workers with more or less similar tasks and to see how their wage distribution behaves as a function of the complexity of the firm's production process. The figure plots the 90th, 75th, 50th, 25 th, and 10th percentiles of the wage distribution at each value of the complexity of the production process.

Figure 4 show clearly that are more or less increasing in the complexity of the production process at all parts of the wage distribution wages. However, what is striking in figure 4 is that the increase is considerably steeper in the higher quantiles. Thus, it seems 


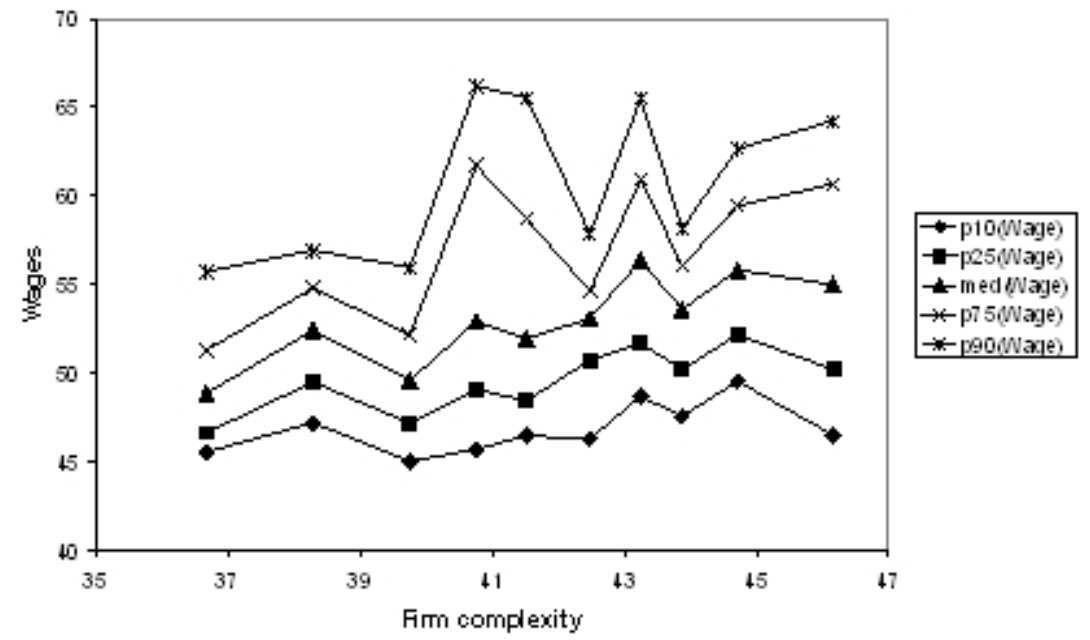

Figure 4: Wage quantiles as a function of the complexity of the production process in the medium complexity group.

that even within tasks of more or less the same complexity, the wages of workers in the upper tail of the wage distribution are more sensitive to changes in the complexity of the production process.

Looking at the effects of the complexity of the firm's production process at different parts of the conditional wage distribution requires running quantile regressions. Unlike in OLS regression, the quantile regressions allow the coefficients of the explanatory variables to vary along the conditional distribution of the dependent variable and therefore it is possible to test for significant differences in the coefficients at different parts of the conditional distribution.

The idea of quantile regressions is to fit the conditional quantiles of the dependent variables with the data. The model we are running is:

$$
\begin{gathered}
w_{i}=\beta_{\theta} \bar{n}_{J(i)}+\eta_{\theta} n_{i}+\gamma_{\theta} X_{i}+v_{\theta_{i}} \\
\operatorname{Quant}_{\theta}\left(w_{i} \mid \bar{n}_{J(i)}, n_{i}, X_{i}\right)=\beta_{\theta} \bar{n}_{J(i)}+\eta_{\theta} n_{i}+\gamma_{\theta} X_{i}
\end{gathered}
$$

where $v_{\theta_{i}}$ is the residual and Quant $\theta_{\theta}\left(w_{i} \mid \bar{n}_{J(i)}, n_{i}, X_{i}\right)$ denotes the $\theta$ th conditional quantile of $w_{i}$. The estimates for parameters $\beta_{\theta}, \eta_{\theta}$, and $\gamma_{\theta}$ are obtained by solving a weighted least absolute deviations minimization problem by linear programming techniques, where weights are chosen depending on which quantile of the conditional distribution of the dependent variable is desired. ${ }^{10}$

The drawback of this technique is that the standard fixed effects methods do not work in this setting. Hence, the residual $v_{\theta_{i}}$ contains the $\theta$ th quantiles of the individual and firm fixed effects as omitted variables and the best way to interpret (9) is to view it as the best linear predictor for the conditional quantile.

Nevertheless, we can try to alleviate the omitted variables problem by estimating (9) within subgroups where individual fixed effects are more or less constant. Here, we chose

\footnotetext{
${ }^{10}$ Technique of quantile regressions has been developed by Koenker and Basset (1978). For a survey on applications see Buchinsky (1998).
} 
to estimate this model separately for our five complexity groups using only the 1996 crosssection. The idea is that the variation in unobservable ability is sufficiently small within complexity levels, so that we can assume $\alpha_{\theta_{i}}$ 's to be fixed.

In table 5 we present the coefficients of the complexity of the firm's production process from quantile regressions of hourly wages on the same variables as in table 3 . We present the estimates at the 10 th, 25 th, 50 th, 75 th and 90th percentiles of the conditional hourly wage distribution. All the equations control for the same co-variates as was done in the OLS analysis above. The pattern of the results is very clear: coefficient of the complexity of the production process increases as we move along the wage distribution in all the task groups. The F-test reported in the last row of each yearly regression clearly rejects the equality of the coefficients. These results mean that the within tasks wage variation increases as the firms adopt more complex production processes. We interpret these results as indicating that the effort-sensitivity of output varies also within levels of complexity.

\section{Conclusions}

According to theoretical models where different tasks are complementary in the production process and output is differentially sensitive to effort in different tasks, the employer will assign relatively more productive workers to more effort-sensitive tasks and pay them higher wages. Wages of all the workers in the firm will increase if the firm decides to switch to a more complex production process because the firm will lose more from potential mistakes in the production line. However, the wages of workers in more effort sensitive tasks will be increased more because output is more sensitive to their effort.

We studied these implications empirically by estimating the effect of the average complexity of the individual's coworkers' tasks on his or her hourly wage at different tasks and at different parts of the conditional wage distribution within tasks. Our argument is that the data on Finnish metal industry are suitable for this purpose because they provide a variable that can be interpreted as a continuous complexity measure.

All the results above indicate that the complexity of the production process tends to increase wages of all workers. That is, workers in identical tasks will earn different wages if the firms they are employed in adopt production processes of different complexity. This effect does not vary a lot across different complexity levels. Thus, switching to more complex production processes does not lead to widening wage differentials between different tasks. However, the wage inequality within tasks increases as the production processes become more complex. This is because the effect of the complexity of the production process is strongest at the high end of the wage distributions within complexity levels.

In our view, these results show that the wages that individual workers earn are not only affected by the task content of their own job but that the characteristics of the production process where they are involved in also play a role. Workers that are part of a more sensitive production process earn higher wages than workers who perform identical tasks in firms that have less sensitive production technologies. The wage dispersion within

tasks is also higher in more complex production processes since other factors that affect the effort-sensitivity of output become more important in more complex processes.

\section{References}

[1]Abowd, J.M, F. Kramarz, and D.N. Margolis, (1999): "High wage workers and high wage firms", Econometrica, 67, 251-333. 
[2]Acemoglu, D., (2002): "Technical change, inequality, and the labor market", Journal of Economic Literature, 40, 7-72.

[3]Autor, D., F. Levy, and R. Murnane, (2001): "The skill content of recent technological change: An empirical exploration", Quarterly Journal of Economics, forthcoming.

[4]Bartel, A., C. Ichniowski, and K. Shaw, (2000): "New technology, human resource practices, and skill requirements: Evidence from plant visits in three industries", mimeo, Carnegie Mellon University.

[5]Bresnahan, T., E. Brynjolfson, and L. Hitt, (2002): "Information technology, workplace organization and the demand for skilled labour", Quarterly Journal of Economics, 117, 339-377.

[6]Buchinsky, M., (1998): "Quantile regression: Practical guide for empirical research", Journal of Human Resources, 33, 88-126.

[7]Dalmazzo, A., (2002): "Technological complexity, wage differentials, and unemployment", Scandinavian Journal of Economics, 104(4), 515-530.

[8]Dalmazzo, A. and P. Scaramozzino, (2000): "It takes two to tango: Process integration and wages", mimeo, Cefims SOAS Discussion Paper no. 08/00.

[9]DiNardo, J. E. and J. S. Pischke, (1997): "The returns to computer use revisited: Have pencils changed the wage structure too?", Quarterly Journal of Economics 112, 291-303.

[10]Doms, M., T. Dunne, and K.R. Troske, (1997): "Workers, wages, and technology", Quarterly Journal of Economics, 253-290.

[11]Dunne, T., L. Foster, J. Haltiwanger, and K. Troske, (2000): "Wage and productivity dispersion in U.S manufacturing: The role of computer investment", NBER Working Paper, 7465.

[12]Entorf, H., M. Gollac, and F. Kramarz, (1999): "New technologies, wages, and worker selection", Journal of Labor Economics, 17, 467-489.

[13]Eriksson, T. and M. Jäntti, (1997): "The distribution of earnings in Finland 19711990", European Economic Review 41, 1736-1779.

[14]Katz, L. F. and D. A. Autor, (1999): "Changes in the wage structure and earnings inequality", in O. Ashernfelter and D. Card (eds) : Handbook of Labor Economics, Vol. 3A, North-Holland, Amsterdam.

[15]Koenker, R., and G. Basset, (1978): "Regression quantiles", Econometrica, 46, 33-50.

[16]Kremer, M., (1993): "The O-ring theory of economic development", Quarterly Journal of Economics, 108, 551-575.

[17]Kremer, M. and E. Maskin, (1996): "Wage inequality and segregation by skill", NBER Working Paper 5718.

[18]Krueger, A.B, (1993): "How computers have changed the wage structure: Evidence from microdata, 1984-1989", Quarterly Journal of Economics, 110, 33-61.

[19]Milrgom, P. \& J. Roberts, (1990): "The economics of modern manufacturing: Technology, Strategy, and Organization", American Economic Review, 80: 511-528. 
[20]Pekkarinen, T. (2002): "Complexity, wages, and the O-ring production function: Evidence from the Finnish panel data", Labour Economics, 9, 531-546.

[21]Sattinger, M., (1979): "Differential rents and the distribution of earnings", Oxford Economic Papers, 31, 60-71.

[22]Shapiro, C. and J. Stiglitz, (1984): "Equilibrium unemployment as a worker discipline device", American Economic Review, 74, 433-444.

[23]Uusitalo, R., (2002): "Changes in the Finnish wage structure: Will demand and supply do?", Scandinavian Journal of Economics 104, 69-85. 
Tables

Table 1 Descriptive statistics, 1996 cross-section

\begin{tabular}{lllllllll} 
& \multicolumn{2}{l}{ The whole sample } & Stayers & & \multicolumn{2}{c}{ Voluntary movers } & \multicolumn{2}{l}{ Mergers } \\
\hline Variable & Mean & Std.dev & Mean & Std.dev & Mean & Std.dev & Mean & Std.dev \\
\hline Gender (Female = 1) & 0.22 & 0.41 & 0.21 & 0.41 & 0.11 & 0.31 & 0.19 & 0.40 \\
Newcomer = 1 & 0.09 & 0.29 & 0.06 & 0.25 & 0.07 & 0.26 & 0.05 & 0.21 \\
Age & 39.03 & 10.84 & 39.47 & 10.19 & 38.05 & 10.10 & 40.00 & 10.37 \\
Seniority & 12.73 & 10.35 & 13.26 & 10.19 & 12.75 & 10.03 & 13.63 & 10.21 \\
$\begin{array}{l}\text { Complexity of the } \\
\text { tasks }\end{array}$ & 42.99 & 4.34 & 43.21 & 4.25 & 43.55 & 4.02 & 44.69 & 4.48 \\
Total hourly wage & 56.08 & 8.73 & 56.43 & 8.45 & 58.29 & 7.58 & 56.90 & 7.51 \\
$\begin{array}{l}\text { Average bonuses } \\
\text { Firm size }\end{array}$ & 0.09 & 0.01 & 0.09 & 0.01 & 0.09 & 0.01 & 0.10 & 0.01 \\
Observations & 1118.66 & 1460.46 & 1162.96 & 1522.76 & 1537.97 & 1858.50 & 216.91 & 134.32 \\
Individuals & 315935 & & 210206 & & 2326 & & 1720 & \\
& 93370 & & 70907 & & 2313 & & 1720 & \\
& & & & & & & &
\end{tabular}

Note: Complexity refers to the occupation-related wage. Seniority is the number of years the person has worked in the metals industry. Total hourly wage is in FIM 1996. Firm size is the number of employees per firm. The whole sample refers to the total number of observations used in the analysis. The stayers are workers who remain in the same firm during 1996-2000. Voluntary movers are workers who leave from a firm that does not close down to a firm that already existed before their arrival. Mergers are situations where the majority of the workers in a closing firm are employed by an already existing firm. 
2a) Distribution of pay for promotees in wage deciles before the promotion

\begin{tabular}{|c|c|c|c|c|c|c|c|c|c|c|c|}
\hline \multirow[b]{2}{*}{ Level } & \multicolumn{10}{|c|}{ Percentage in each wage decile } & \multirow[t]{2}{*}{ Total } \\
\hline & 0 & 1 & 2 & 3 & 4 & 5 & 6 & 7 & 8 & 9 & \\
\hline 33 & 21.24 & 8.37 & 6.09 & 7.74 & 11.41 & 13.89 & 12.68 & 7.93 & 4.19 & 6.47 & 100.00 \\
\hline 34 & 16.62 & 7.30 & 13.35 & 12.85 & 12.09 & 8.56 & 8.82 & 7.56 & 2.77 & 10.08 & 100.00 \\
\hline 35 & 17.75 & 10.86 & 7.32 & 9.76 & 12.87 & 10.74 & 8.60 & 7.02 & 3.60 & 11.47 & 100.00 \\
\hline 36 & 14.65 & 8.88 & 13.19 & 13.19 & 10.76 & 9.18 & 8.21 & 5.96 & 5.29 & 10.70 & 100.00 \\
\hline 37 & 16.92 & 15.71 & 12.17 & 12.61 & 10.62 & 7.41 & 4.42 & 6.08 & 5.42 & 8.63 & 100.00 \\
\hline 38 & 12.57 & 10.10 & 9.91 & 11.93 & 10.15 & 10.45 & 10.99 & 7.34 & 6.01 & 10.55 & 100.00 \\
\hline 39 & 9.20 & 9.75 & 11.95 & 12.40 & 9.35 & 10.90 & 11.80 & 11.80 & 6.45 & 6.40 & 100.00 \\
\hline 40 & 10.61 & 8.30 & 11.31 & 11.89 & 11.56 & 9.84 & 9.91 & 13.11 & 6.20 & 7.27 & 100.00 \\
\hline 41 & 10.00 & 9.44 & 14.15 & 14.33 & 13.15 & 11.05 & 11.40 & 6.47 & 4.28 & 5.72 & 100.00 \\
\hline 42 & 9.19 & 9.63 & 10.45 & 10.84 & 12.61 & 11.00 & 13.12 & 8.61 & 6.13 & 8.41 & 100.00 \\
\hline 43 & 9.28 & 9.00 & 10.74 & 12.71 & 12.65 & 13.10 & 9.73 & 9.22 & 7.42 & 6.13 & 100.00 \\
\hline 44 & 8.94 & 9.72 & 10.64 & 13.05 & 13.49 & 12.31 & 11.70 & 7.71 & 4.86 & 7.58 & 100.00 \\
\hline 45 & 7.45 & 7.05 & 8.45 & 12.71 & 14.64 & 15.44 & 14.24 & 8.65 & 6.05 & 5.32 & 100.00 \\
\hline 46 & 8.55 & 8.64 & 9.67 & 10.78 & 9.75 & 13.94 & 13.52 & 11.46 & 5.56 & 8.13 & 100.00 \\
\hline 47 & 1.92 & 0.00 & 0.00 & 13.46 & 17.31 & 25.00 & 19.23 & 7.69 & 7.69 & 7.69 & 100.00 \\
\hline 48 & 8.35 & 6.74 & 9.15 & 11.40 & 17.50 & 16.21 & 10.43 & 8.19 & 5.94 & 6.10 & 100.00 \\
\hline 49 & 1.92 & 1.92 & 7.69 & 15.38 & 26.92 & 9.62 & 13.46 & 1.92 & 13.46 & 7.69 & 100.00 \\
\hline Total & 11.55 & 9.31 & 10.59 & 11.94 & 12.06 & 11.53 & 10.98 & 8.70 & 5.53 & 7.82 & 100.00 \\
\hline
\end{tabular}

Note: Promotees are workers who move from a given complexity level to a higher one. Complexity levels are constructed by aggregating the occupation-related wages into integers. Rows report the distribution of promotees in the wage deciles of the within firm wage distibution of given level before the promotion takes places. Columns are deciles of the within firm wage distribution of that level. 
2b) Distribution of pay for promotees in wage deciles after the promotion

\begin{tabular}{|c|c|c|c|c|c|c|c|c|c|c|c|}
\hline \multirow[b]{2}{*}{ Level } & \multicolumn{10}{|c|}{ Percentage in each wage decile } & \multirow[t]{2}{*}{ Total } \\
\hline & 0 & 1 & 2 & 3 & 4 & 5 & 6 & 7 & 8 & 9 & \\
\hline 34 & 0.00 & 0.00 & 0.00 & 0.00 & 0.00 & 0.00 & 0.00 & 100.00 & 0.00 & 0.00 & 100.00 \\
\hline 35 & 3.47 & 3.11 & 10.30 & 22.28 & 25.99 & 19.76 & 8.14 & 2.63 & 1.68 & 2.63 & 100.00 \\
\hline 36 & 10.28 & 9.40 & 12.78 & 16.30 & 17.91 & 10.57 & 8.66 & 3.08 & 3.82 & 7.20 & 100.00 \\
\hline 37 & 23.53 & 14.29 & 9.24 & 11.76 & 12.61 & 7.56 & 5.04 & 3.36 & 2.94 & 9.66 & 100.00 \\
\hline 38 & 15.72 & 12.59 & 15.65 & 12.67 & 14.98 & 9.09 & 8.20 & 3.73 & 2.68 & 4.69 & 100.00 \\
\hline 39 & 9.45 & 9.55 & 15.68 & 21.01 & 10.95 & 11.26 & 8.34 & 8.04 & 3.02 & 2.71 & 100.00 \\
\hline 40 & 12.37 & 11.56 & 12.28 & 13.72 & 13.98 & 11.94 & 9.61 & 7.84 & 3.64 & 3.05 & 100.00 \\
\hline 41 & 13.62 & 11.36 & 16.64 & 12.81 & 12.05 & 9.54 & 7.72 & 7.72 & 4.52 & 4.02 & 100.00 \\
\hline 42 & 15.66 & 12.43 & 10.56 & 14.21 & 14.21 & 9.11 & 8.37 & 6.67 & 3.81 & 4.97 & 100.00 \\
\hline 43 & 12.86 & 13.65 & 15.79 & 18.64 & 12.90 & 9.84 & 6.96 & 5.21 & 1.88 & 2.27 & 100.00 \\
\hline 44 & 13.27 & 13.88 & 13.73 & 15.35 & 13.39 & 11.34 & 8.27 & 4.35 & 2.45 & 3.95 & 100.00 \\
\hline 45 & 10.74 & 13.88 & 15.31 & 17.32 & 13.26 & 9.65 & 7.80 & 5.41 & 3.36 & 3.27 & 100.00 \\
\hline 46 & 14.95 & 10.01 & 10.13 & 12.06 & 13.77 & 14.24 & 10.36 & 6.33 & 3.40 & 4.75 & 100.00 \\
\hline 47 & 12.62 & 12.62 & 8.74 & 14.56 & 15.53 & 8.74 & 10.68 & 0.97 & 6.80 & 8.74 & 100.00 \\
\hline 48 & 12.97 & 9.61 & 10.55 & 13.50 & 16.86 & 12.32 & 10.38 & 5.96 & 3.42 & 4.42 & 100.00 \\
\hline 49 & 15.36 & 10.24 & 14.73 & 17.64 & 10.30 & 8.60 & 7.27 & 5.75 & 5.12 & 4.99 & 100.00 \\
\hline 50 & 11.21 & 9.01 & 13.11 & 13.51 & 16.12 & 15.42 & 7.51 & 5.21 & 3.90 & 5.01 & 100.00 \\
\hline Total & 13.03 & 11.54 & 13.25 & 15.33 & 14.09 & 11.21 & 8.45 & 5.72 & 3.31 & 4.08 & 100.00 \\
\hline
\end{tabular}

Note: Promotees are workers who move from a given complexity level to a higher one. Complexity levels are constructed by aggregating the occupation-related wages into integers. Rows report the distribution of promotees in the wage deciles of the within firm wage distibution of given level after the promotion takes places. Columns are deciles of the within firm wage distribution of that level. 
Table 3 Regression analysis of the wage function

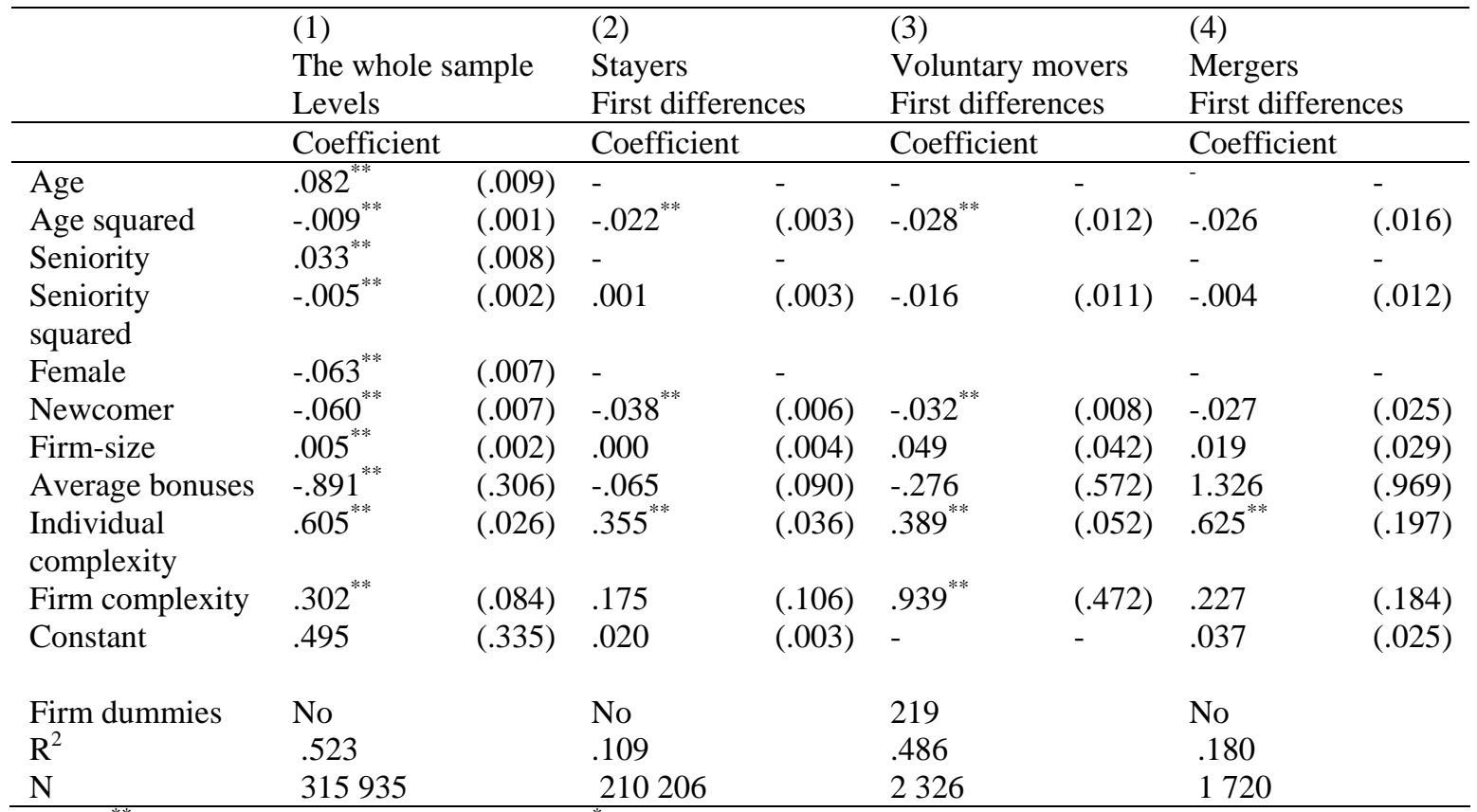

Note: ${ }^{* *}$ refers to significance at $5 \%$-level. ${ }^{*}$ refers to significance at $10 \%$-level. Age is divided by ten.

Seniority is the number of years the individual has worked in the firm divided by ten. Firm-size refers to the number of employees in the firm divided by 100. Individual complexity is measured as the log of the real occupation-related wage. Firm complexity is measured as the mean of the log real occupation-related wages of individual's co-workers.

(1) The dependent variable is the log of real hourly wage. Standard errors, reported in parenthesis, are corrected for heteroscedasticity using Huber-White formula accounting for the fact that there are multiple observations per firm.

(2) Stayers are workers who remain in the same firm between $t$ and $t+1$. The dependent variable is the first difference of the log of real hourly wage. All the explanatory variables are in first differences. Standard errors, reported in parenthesis, are corrected for heteroscedasticity using Huber-White formula accounting for the fact that there are multiple observations per firm.

(3) Voluntary movers are workers who leave from a firm that does not close down to a firm that already existed before their arrival. The dependent variable is the first difference of the log of real hourly wage. All the explanatory variables are in first differences. Equation includes 219 firm dummies in first differences as additional explanatory variables. Standard errors, reported in parenthesis, are corrected for heteroscedasticity using Huber-White formula.

(4) Mergers are situations where more than $50 \%$ of the workforce of a firm that is closed down is absorbed by a firm that already existed before the arrival of the new workers. The dependent variable is first difference of the log real hourly wage. All the explanatory variables are in first differences. Standard errors, reported in parenthesis, are corrected for heteroskedasticity using Huber-White formula accounting for the fact that there are multiple observations per firm. 
Table 4 Regression analysis of the wage function with interaction of individual and firm complexity

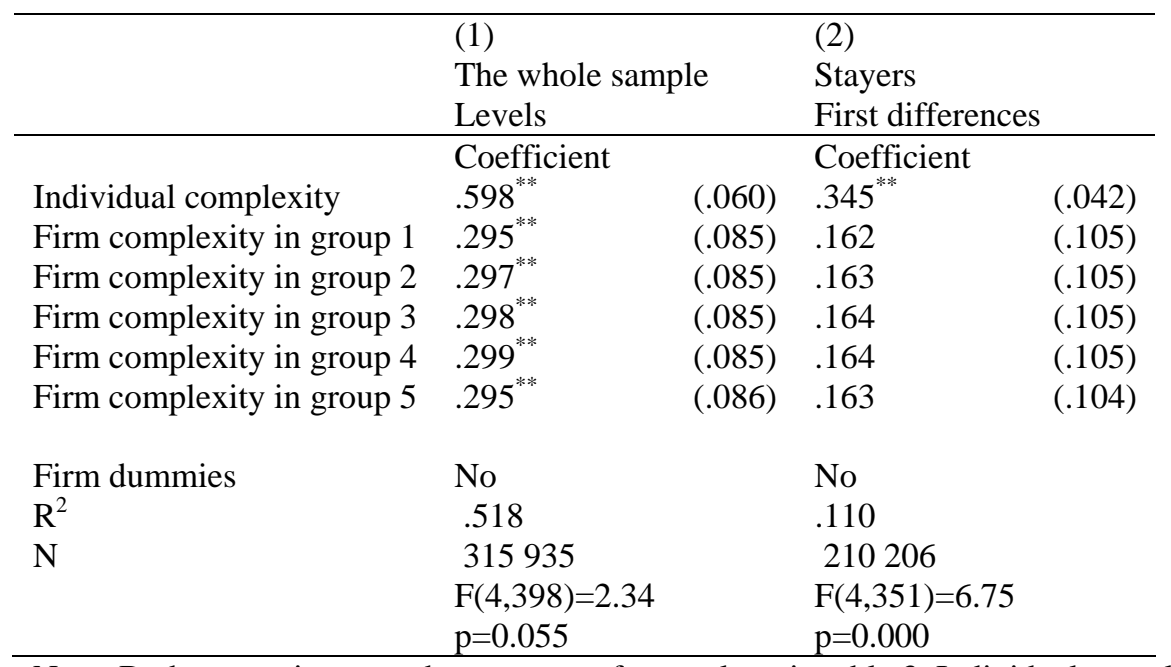

Note: Both regressions use the same set of controls as in table 3. Individual complexity refers to refers to the individual's own log occupation-related wage. Firm complexity refers to the average of the individual's co-workers occupation-related wages. Groups 1 to 5 refer complexity levels that were constructed by splitting the axis of individual complexity into five quantiles. Firm complexity in groups 1 to 5 refers to the interaction terms of the complexity levels and the complexity of the production process. The last row reports the F-test statistic of test of the equality of the coefficients of firm complexity in groups 1 to 5 . All the explanatory variables are in first differences. Standard errors, reported in parenthesis, are corrected for heteroskedasticity using Huber-White formula accounting for the fact that there are multiple observations per firm. 
Table 5 Estimates of the coefficients of log firm complexity from quantile regressions. The $0.10,0.25,0.50$, 0.75 , and $0.90^{\text {th }}$ quantiles of the conditional wage distribution in five groups of individual complexity. 1996 cross-section.

\begin{tabular}{llllll}
\hline Complexity group 1 & $0.10^{\text {th }}$ quantile & $0.25^{\text {th }}$ quantile & $0.50^{\text {th }}$ quantile & $0.75^{\text {th }}$ quantile & $0.90^{\text {th }}$ quantile \\
\hline Firm complexity & 0.321 & 0.422 & 0.509 & 0.609 & 0.791 \\
(Bootstrap Std. Error) & 0.023 & 0.023 & 0.036 & 0.041 & 0.056 \\
Pseudo R & 0.160 & 0.129 & 0.130 & 0.156 & 0.189 \\
\hline
\end{tabular}

$\mathrm{F}(4,8484)=18.37$

\begin{tabular}{llllll}
\hline Complexity group 2 & $0.10^{\text {th }}$ quantile & $0.25^{\text {th }}$ quantile & $0.50^{\text {th }}$ quantile & $0.75^{\text {th }}$ quantile & $0.90^{\text {th }}$ quantile \\
\hline Firm complexity & 0.202 & 0.218 & 0.289 & 0.417 & 0.591 \\
(Bootstrap Std. Error) & 0.024 & 0.022 & 0.021 & 0.027 & 0.036 \\
Pseudo R ${ }^{2}$ & 0.112 & 0.102 & 0.115 & 0.129 & 0.122 \\
\hline \multicolumn{7}{r}{$\mathrm{F}(4,12531)=27.17$} \\
\hline
\end{tabular}

\begin{tabular}{|c|c|c|c|c|c|}
\hline Complexity group 3 & $0.10^{\text {th }}$ quantile & $0.25^{\text {th }}$ quantile & $0.50^{\text {th }}$ quantile & $0.75^{\text {th }}$ quantile & $0.90^{\text {th }}$ quantile \\
\hline Firm complexity & 0.147 & 0.367 & 0.454 & 0.570 & 0.489 \\
\hline (Bootstrap Std. Error) & 0.030 & 0.025 & 0.033 & 0.052 & 0.060 \\
\hline Pseudo $\mathrm{R}^{2}$ & 0.112 & 0.112 & 0.096 & 0.092 & 0.077 \\
\hline \multicolumn{6}{|c|}{$F(4,9$ 883) $=18.94$} \\
\hline Complexity group 4 & $0.10^{\text {th }}$ quantile & $0.25^{\text {th }}$ quantile & $0.50^{\text {th }}$ quantile & $0.75^{\text {th }}$ quantile & $0.90^{\text {th }}$ quantile \\
\hline Firm complexity & 0.061 & 0.205 & 0.258 & 0.434 & 0.389 \\
\hline (Bootstrap Std. Error) & 0.021 & 0.031 & 0.019 & 0.025 & 0.043 \\
\hline Pseudo $\mathrm{R}^{2}$ & 0.112 & 0.125 & 0.109 & 0.089 & 0.082 \\
\hline
\end{tabular}

\begin{tabular}{llllll}
\hline Complexity group 5 & $0.10^{\text {th }}$ quantile & $0.25^{\text {th }}$ quantile & $0.50^{\text {th }}$ quantile & $0.75^{\text {th }}$ quantile & $0.90^{\text {th }}$ quantile \\
\hline Firm complexity & 0.155 & 0.224 & 0.362 & 0.518 & 0.621 \\
(Bootstrap Std. Error) & 0.018 & 0.017 & 0.019 & 0.028 & 0.040 \\
Pseudo R & 0.101 & 0.105 & 0.093 & 0.083 & 0.081 \\
\hline
\end{tabular}

$\mathrm{F}(4,15993)=41.49$

Note: Quantile regression of wages on the variables in table $1.0 .10^{\text {th }}, 0.25^{\text {th }}, 0.50^{\text {th }}, 0.75^{\text {th }}$, and $0.90^{\text {th }}$ quantiles of the wage distribution are fitted to the linear regression model. Standard errors are obtained by bootstrapping with 100 replications. Last row presents the F-test statistic under the null hypothesis that the coefficients of firm complexity are equal at the five quantiles of the conditional wage distribution. All equations include the same controls as the equation in the first column of table 3 , excluding the complexity of the individual's own tasks which is approximately constant within complexity groups. 